Available online on 15.02.2020 at http://jddtonline.info
Open Access to Pharmaceutical and Medical Research
unrestricted non-commercial use, provided the original work is properly cited

Open@Access

Research Article

\title{
Bilateral adrenal hyperplasia; a common cause of drug-refractory hypertension yet amenable to medical treatment
}

\author{
Kamel El-Reshaid *, Shaikha Al-Bader ** \\ *Department of Medicine, Faculty of Medicine, Kuwait University, Kuwait \\ ** Department of Medicine, Nephrology unit, Amiri hospital, Ministry of health, Kuwait
}

\begin{abstract}
Over the past 4 and 1/2 years, a total of 97 patients had hypertension yet lacked clinical, laboratory and radiological evidence of renal, renovascular and endocrine disease were investigated for A/R ratio. High A/R was detected in 30 patients. Five patients had unilateral adrenal adenoma and 1 had cancer while 24 patients $(24.7 \%)$ had bilateral enlargements indicating bilateral adrenal hyperplasia (BAH). Our study has shown that BAH is: (a) easily diagnosed with a combination of A/R ratio and CT scan of the adrenal gland, (b) responsible for $24.7 \%$ of hypertension cases, (c) associated with moderate to severe hypertension that may require 2-4 antihypertensives, (d) associated with hypokalemia in only in $54 \%$ of the cases, (e) not controlled with a single daily dose of Spironolactone (S) and $1 / 2$ the cases require 50 mg/day. Moreover, it has shown that $\mathrm{S}$ treatment was not associated with significant hyperkalemia yet gynecomastia and erectile dysfunction were common side effects. Interestingly; and despite normalization of A/R ratio, most patients continue to require antihypertensive drugs though the number and dosage were less. The latter phenomenon was more evident in those with higher initial A/R ratio and longer duration of hypertension. Nephroangiosclerosis is the most plausible explanation for it. In conclusion; BAH is not a rare disease and should be considered in cases of refractory hypertension.
\end{abstract}

Keywords: Aldosterone, Aldosterone/Renin ratio, hypertension, Spironolactone.

Article Info: Received 22 Nov 2019; Review Completed 14 Jan 2020; $\quad$ Accepted 25 Jan 2020; Available online 15 Feb 2020

Cite this article as:

El-Reshaid K, Al-Bader S, Bilateral adrenal hyperplasia; a common cause of drug-refractory hypertension yet amenable to medical treatment, Journal of Drug Delivery and Therapeutics. 2020;10(1-s):79-82

http://dx.doi.org/10.22270/jddt.v10i1-s.3862

*Address for Correspondence:

Dr. Kamel El-Reshaid, Professor, Dept. of Medicine, Faculty of Medicine, Kuwait University, P O Box 24923, 13110 Safat, Kuwait

\section{INTRODUCTION}

Primary hyperaldosteronism (PH) refers to overproduction of aldosterone. It used to be an under-recognized cause of hypertension yet in recent studies it has reached a prevalence of $10 \%$ in hypertensive patients [1]. It can be associated with bilateral adrenal hyperplasia (BAH) in 66\% of cases, adrenal adenoma in 33\%, unilateral adrenal hyperplasia in $2 \%$, aldosterone-producing adrenocortical carcinoma in $<1 \%$, familial hyperaldosteronism in $<2 \%$ and ectopic aldosterone-producing adenoma or carcinoma in < $0.1 \%$ of cases [2]. On the other hand, secondary hyperaldosteronism is derived from an elevated renin associated with renal hypoperfusion due to intravascular volume contraction, poor perfusion pressure, renovascular disorders and parenchymal kidney disease [3]. While the treatment of secondary hyperaldosteronism is directed to the underlying cause; treatment of BAH is by aldosteroneantagonists [4]. Spironolactone acts primarily on the principal cells of the distal convoluted tubules and medullary collecting ducts leading to activation of sodiumpotassium ATPase. Hence it leads to sodium and water reabsorption and potassium secretion [5]. Initial attempts to limit diagnosis of $\mathrm{PH}$ to "hypertension with hypokalemia and alkalosis" and laboratory diagnosis with high serum or 24-hour urine aldosterone lead to under-estimation of the prevalence of the disorder. Subsequently, most of those cases were misdiagnosed and were categorized as "essential hypertension" [4]. Recently, high aldosterone/renin ratio (A/R ratio) has been proposed as a better marker for $\mathrm{PH}$ compared to the previous tests since they are affected by age, sex, posture, hydration state, sodium-intake, storage conditions, medications (antihypertensives, diuretics and contraceptives) and renal function. Such marker for PH led to improvement in diagnosis of its subclinical states and their prevalence [6]. In the current study; we present our experience $\mathrm{BAH}$ in our area and its management. 


\section{PATIENTS AND METHODS:}

\section{Study design:}

Patients with hypertension who attended Dr. El-Reshaid kidney clinic from $1^{\text {st }}$ January 2014 to $31^{\text {st }}$ June 2019 were analyzed prospectively for BAH. The clinic was established in 1997 in the center of Kuwait city. It is a referral center and with adequate diagnostic as well as therapeutic facilities to care for both in- and out-patients with all medical and renal diseases.

\section{Inclusion criteria:}

Patients were included, in the study, if they had BAH. The latter was defined as hypertension with diastolic blood pressure above $90 \mathrm{~mm} \mathrm{Hg}$ and associated with: (a) high A/R ratio, males: 10.2-23.7 and females: 15.7-41.9 [7], (b) normal or bilaterally enlarged adrenal glands without masses by computerized axial tomography (CAT) scanning, (c) normal capoten-renogram, and (d) normal DMSA nuclear scan. Aldosterone antagonists were discontinued 3 weeks prior to evaluation with $\mathrm{A} / \mathrm{R}$ ratio.

\section{Exclusion criteria:}

1- High serum free thyroxin, catecholamines, and cortisol.

2- Patients with acromegaly (clinical features and positive oral glucose tolerance test)

3- Patients with creatinine clearance $<60 \mathrm{ml} /$ minute.

4- Patients with volume depletion, decrease effective intravascular volume i.e. heart failure, nephrotic syndrome or liver disease.

\section{Initial assessment:}

Patients with hypertension and high $\mathrm{A} / \mathrm{R}$ ratio had detailed laboratory and radiological testing to satisfy inclusion criteria. The laboratory ones included: (a) serum urea, creatinine and 24 hour urine collection for creatinine clearance and protein output, (b) serum electrolytes viz. sodium, potassium and bicarbonate content, uric acid (c) urine routine and microscopy, (c) ultrasound of the abdomen for liver, spleen, kidneys sizes and abnormality as well as the presence of ascites, (d) echocardiogram to assess for pericardial, valvular disease and LVEF, (e) capoten renogram to assess for renovascular disease, (f) DMSA nuclear scan to rule out renal scars, and finally (g) CT scan of the adrenal glands to ensure normal adrenals or bilateral hyperplasia.

\section{Introduction of Spironolactone (S):}

The drug was started twice/weekly and the dose was increased further to thrice/weekly by week 2 then once/daily by week 3 if no hypokalemia. The dosage of antihypertensive drugs was reduced or omitted if blood pressure drops. The dose of S was increased after 1 month if $A / R$ ratio remained above normal range and blood pressure as well as potassium level permits.

\section{Follow up testing:}

Included; clinical and serum testing for renal function and electrolytes every 2 weeks. A/R ratio was done after 1 and 2 month of follow up.

\section{Statistical analysis:}

SPSS statistical package version 25 was used for data entry and processing. The $\mathrm{p}$-value $\leq 0.05$ was used as the cut-off level for significance. Mean and standard deviation were used to describe the normally distributed variables viz. age, duration of hypertension. Since A/R ratio, duration of follow up while on $S$ therapy and number of antihypertensive drugs used before and after starting $\mathrm{S}$ were not normally distributed; they were expressed as median (interquartile range). Moreover, comparison of changes in $A / R$ ratio at different times (0, 1 and 2 months) was done using Wilcoxon Signed rank test while student t-test was used to compare age and duration of hypertension between males and females.

\section{RESULTS}

\section{Demographical data:}

Over the past 4 and $1 / 2$ years, a total of 97 patients had hypertension yet lacked clinical, laboratory and radiological evidence of renal, renovascular and endocrine disease were investigated for $A / R$ ratio. High $A / R$ was detected in 30 patients. Five patients had unilateral adrenal adenoma and 1 had cancer while 24 patients $(24.7 \%)$ had bilateral enlargements. The latter group of patients has satisfied the criteria of BAH and hence they were included in the study. Their demographical data and results of their tests on follow up are shown in table 1 and summery of the statistical analysis is summarized in table 2 . Females constituted $14 / 24(58 \%)$ and had a mean age $(+S D)$ of $36.7 \pm 9$ while the latter was $35.8 \pm 6$ in males. The median (IQ) duration of hypertension was 3 (4) years in females while it was 4 (3) in males. Both parameters (age and duration of hypertension) were statistically similar between sexes. Hypokalemia was detected only in 13 patients (54\%).

\section{Patients' characteristics:}

Patients with high $A / R$ ratio had moderate to severe hypertension. To achieve acceptable level of normotension, 2 patients had required a combination of 4 different groups of drugs and 16 had required 3 drugs. None had required a single drug-therapy.

\section{Efficacy of S:}

1- With $25 \mathrm{mg}$ daily, all patients had improvement in their hypertension and A/R. However, by 1 month, only 12 patients had achieved normal A/R ratio. Their $\mathrm{A} / \mathrm{R}$ ratio did not change significantly by the end of the second month. The 12 patients, who did not achieve normal levels of $A / R$ ratio, by the first month, had further improvement with $50 \mathrm{mg}$ daily. However, 2 patients (n: $7 \& 21$ ) had mildly elevated A/R ratio 1 month after increment of $S$ to $50 \mathrm{mg} /$ day.

2- Overall, blood pressure was well controlled and with less medications after starting $\mathrm{S}(\mathrm{p}=<0.002)$. However, and despite normalization of $\mathrm{A} / \mathrm{R}$ ratio; 18 patients (75\%) were still requiring antihypertensive drugs. In the latter patients, the drug-combinations were $\leq 2$. Moreover, higher the number of initial and final drug therapy were associated with longer duration of hypertension prior to inclusion in the study and vice versa.

\section{Side effects of $S$ :}

In general the drug was well tolerated except for 4 patients with severe gynecomastia and 3 with erectile dysfunction. By the first month, none of the patients had hypokalemia. With S treatment and diet, none of the patients had significant hyperkalemia that indicated discontinuation of S therapy. 
Table 1. Demographical data on the patients with adrenal hyperplasia and their response to Spironolactone

\begin{tabular}{|c|c|c|c|c|c|c|c|c|c|c|c|}
\hline \multirow[t]{2}{*}{$\begin{array}{l}\dot{\Xi} \\
\text { है } \\
\text { है }\end{array}$} & \multirow[t]{2}{*}{$\stackrel{x}{\infty}$} & \multirow{2}{*}{ 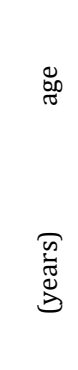 } & \multirow{2}{*}{ 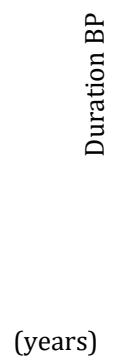 } & \multirow[t]{2}{*}{ 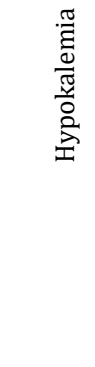 } & \multicolumn{3}{|c|}{ 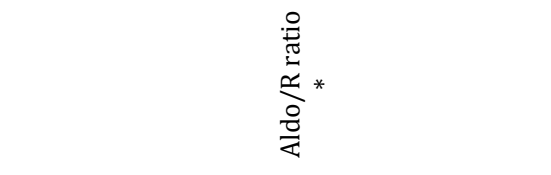 } & \multirow{2}{*}{ 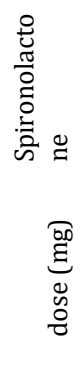 } & \multirow{2}{*}{ 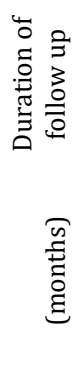 } & \multirow[b]{2}{*}{$\stackrel{\text { : }}{\stackrel{\Xi}{\Xi}}$} & \multirow{2}{*}{ 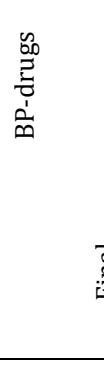 } \\
\hline & & & & & $\begin{array}{c}\text { (pmol/ } \\
\text { ng) }\end{array}$ & 1 month & 2 months & & & & \\
\hline 1 & M & 41 & 5 & $\mathrm{Y}$ & 126 & 50 & 21 & 50 & 6 & 3 & 1 \\
\hline 2 & $\mathrm{~F}$ & 26 & 2 & $\mathrm{~N}$ & 54 & 31 & 33 & 25 & 6 & 2 & 1 \\
\hline 3 & $\mathrm{~F}$ & 53 & 7 & $\mathrm{Y}$ & 137 & 58 & 38 & 50 & 6 & 3 & 2 \\
\hline 4 & $\mathrm{~F}$ & 24 & 5 & $\mathrm{Y}$ & 103 & 46 & 32 & 50 & 6 & 3 & 1 \\
\hline 5 & $\mathrm{~F}$ & 33 & 1 & $\mathrm{~N}$ & 96 & 41 & 41 & 25 & 6 & 3 & 1 \\
\hline 6 & M & 28 & 2 & $\mathrm{Y}$ & 92 & 47 & 20 & 50 & 6 & 3 & 1 \\
\hline 7 & M & 42 & 6 & $\mathrm{Y}$ & 129 & 62 & 33 & 50 & 6 & 4 & 2 \\
\hline 8 & M & 34 & 5 & $\mathrm{~N}$ & 90 & 43 & 21 & 50 & 6 & 3 & 1 \\
\hline 9 & M & 41 & 6 & $\mathrm{Y}$ & 80 & 51 & 19 & 50 & 6 & 3 & 1 \\
\hline 10 & $\mathrm{~F}$ & 46 & 5 & $\mathrm{Y}$ & 113 & 53 & 35 & 50 & 6 & 3 & 1 \\
\hline 11 & $\mathrm{~F}$ & 35 & 4 & Y & 136 & 38 & 39 & 25 & 6 & 3 & 2 \\
\hline 12 & M & 32 & 1 & $\mathrm{~N}$ & 91 & 21 & 22 & 25 & 6 & 3 & 1 \\
\hline 13 & $\mathrm{~F}$ & 46 & 3 & $\mathrm{Y}$ & 138 & 41 & 41 & 25 & 6 & 3 & 2 \\
\hline 14 & $\mathrm{~F}$ & 45 & 6 & $\mathrm{Y}$ & 141 & 59 & 37 & 50 & 5 & 4 & 2 \\
\hline 15 & $\mathrm{~F}$ & 32 & 4 & $\mathrm{Y}$ & 125 & 71 & 41 & 50 & 4 & 3 & 1 \\
\hline 16 & $\mathrm{~F}$ & 39 & 2 & $\mathrm{~N}$ & 79 & 13 & 15 & 25 & 4 & 3 & 1 \\
\hline 17 & $\mathrm{~F}$ & 42 & 1 & $\mathrm{~N}$ & 84 & 43 & 41 & 25 & 3 & 2 & 0 \\
\hline 18 & $\mathrm{~F}$ & 37 & 1 & $\mathrm{~N}$ & 77 & 29 & 31 & 25 & 3 & 2 & 0 \\
\hline 18 & $\mathrm{M}$ & 29 & 2 & $\mathrm{Y}$ & 83 & 42 & 15 & 50 & 3 & 3 & 1 \\
\hline 20 & $\mathrm{M}$ & 38 & 2 & $\mathrm{~N}$ & 54 & 11 & 13 & 25 & 3 & 2 & 0 \\
\hline 21 & $\mathrm{M}$ & 43 & 5 & $\mathrm{Y}$ & 137 & 42 & 29 & 50 & 3 & 3 & 2 \\
\hline 22 & $\mathrm{M}$ & 30 & 3 & $\mathrm{~N}$ & 94 & 22 & 21 & 25 & 2 & 3 & 1 \\
\hline 23 & $\mathrm{~F}$ & 24 & 2 & $\mathrm{~N}$ & 98 & 37 & 39 & 25 & 2 & 2 & 1 \\
\hline 24 & $\mathrm{~F}$ & 32 & 1 & $\mathrm{~N}$ & 64 & 9 & 11 & 25 & 2 & 2 & 0 \\
\hline
\end{tabular}

Abbreviations: BP: hypertension, F: female, M: males, Y: present, N: absent, Aldo/R ratio: Aldosterone/Renin ration

* Reference range for M: 10.2-23.7 \& F: 15.7-41.9

Table 2. Summery of the statistical analysis of the results of the study

\begin{tabular}{|c|c|c|c|c|}
\hline$\underline{\underline{\text { Parameter }}}$ & $\begin{array}{c}\text { Total } \\
\text { (n: 24) }\end{array}$ & $\begin{array}{l}\text { Males } \\
(\mathrm{n}: 10)\end{array}$ & $\begin{array}{c}\text { Females } \\
(\mathrm{n}: 14)\end{array}$ & $P$ P-value \\
\hline Age: & $36+8$ & $36+6$ & $37+9$ & NS \\
\hline Duration of hypertension: & 3 (3), (1-7) & $4(3),(1-6)$ & $3(4),(1-7)$ & NS \\
\hline \multicolumn{5}{|l|}{ Aldosterone/Renin ratio: } \\
\hline Time 0: & & $98(45)$ & $101(58)$ & \\
\hline Time 1 month: & & $43(29)$ & $41(24)$ & \\
\hline Time 2 months & & $21(6)$ & $38(9)$ & \\
\hline$P$-value & & 0.002 & 0.001 & \\
\hline Duration of follow up: & $6(3),(2-6)$ & $6(3),(2-6)$ & $5.5(3),(2-6)$ & NS \\
\hline \multicolumn{5}{|l|}{ Number of BP drugs: } \\
\hline Initial: & $3(0)$ & $3(0)$ & $3(1)$ & \\
\hline Final: & $1(0)$ & $1(0)$ & $1(1)$ & \\
\hline$P$-value & & 0.002 & 0.002 & \\
\hline Hypokalemia: & $13 / 24(54 \%)$ & $6 / 10(60 \%)$ & $7 / 14(50)$ & \\
\hline 50 mg requirement: & $12 / 24(60 \%)$ & $7 / 10(70 \%)$ & $5 / 14(38 \%)$ & \\
\hline
\end{tabular}




\section{DISCUSSION}

Hypertension is a major risk factor for coronary artery disease, stroke, heart failure, atrial fibrillation, peripheral arterial disease, vision loss, chronic kidney disease, and dementia [8].

It has been classified as either primary (essential) or secondary hypertension. Nearly 95\% of cases are considered primary and has been attributed to nonspecific lifestyle and genetic factors. The remaining 5\% of secondary cases were attributed to chronic kidney disease, narrowing of the kidney arteries, an endocrine disorder, or the use of birth control pills [9]. Kidney disease was considered the most common secondary cause of hypertension while endocrine ones viz. Cushing's syndrome, hyperthyroidism, acromegaly, hyperaldosteronism, and pheochromocytoma [10]. Our study has shown that BAH is: (a) can be easily diagnosed with a combination of $A / R$ ratio and CT scan of the adrenal gland, (b) responsible for $24.7 \%$ of hypertension cases, (c) associated with moderate to severe hypertension that may require 2-4 antihypertensives, (d) associated with hypokalemia in only in $54 \%$ of the cases, (e) not controlled with a single daily dose of $\mathrm{S}$ and $1 / 2$ the cases require $50 \mathrm{mg} /$ day. Moreover, it has shown that $S$ treatment was not associated with significant hyperkalemia yet gynecomastia and erectile dysfunction were common side effects. Fortunately, in 1983, a selective aldosterone receptor antagonist (SARA) was approved for medical use in USA [11]. The latter has similar diuretic effect of $S$ yet without its antiandrogenic effect. It is relatively costly and hence can be reserved for patients with significant side effects following $S$ therapy. Interestingly; and despite normalization of $A / R$ ratio, most patients continue to require antihypertensive drugs. Since the drug-combination was less in those with shorter duration of hypertension prior to inclusion and higher in those with long-history of disease; its pathogenesis is related to Nephroangiosclerosis. The latter includes permanent damage to the arterioles (arteriosclerosis) that leads to tubular atrophy, interstitial fibrosis and glomerular ischemia [12].]. Hence, and theoretically, ACEI and ARB are the drugs of choice following $\mathrm{S}$ treatment of BAH. Unfortunately, hyperkalemia can be a major limiting factor for such drug combination. Ultimately, the management plan should be individualized based on the condition of the patient including his co-morbid conditions, stage of hypertension and his kidneys. In conclusion; BAH is not a rare disease and should be considered in cases of refractory hypertension. Treatment with $\mathrm{S}$ can normalize $\mathrm{A} / \mathrm{R}$ ratio and lower the drug-requirements but not for those long-standing hypertension.

\section{REFERENCES:}

1- Schirpebach C, Reincke M. Primary aldosteronism: current knowledge and controversies in Conn's syndrome. Nature Clin Pract Endocrinol Met 2007; 3: 220-227.

2- Kronenberg HM. Williams textbook of endocrinology $\left(11^{\text {th }}\right.$ ed). Philadelphia: Saunders/Elsevier. ISBN 978-1-41602911-3.

3- Nieman LK. Adrenal cortex. In: Goldman L, Schafer AI, eds. Goldman-Cecil Medicine. 25th ed. Philadelphia, PA: Elsevier Saunders; 2016: chap 227.

4- Funder, John W.; Carey, Robert M.; Fardella, Carlos; GomezSanchez, Celso E.; Mantero, Franco; Stowasser, Michael; Young, William F.; Montori, Victor M. (2008). "Case Detection, Diagnosis, and Treatment of Patients with Primary Aldosteronism". J Clin Endocrinol Metab 2008; 93: 32663281

5- O'Neil RG. Aldosterone regulation of sodium and potassium transport in the cortical collecting duct. Semin Nephrol 1990; 10: 365-374.

6- Mulatero P, Dluhy RG, Giacchetti G, Boscaro M, Veglio F, Sterwart PM. Diagnosis of primary hyperaldosteronism: from screening to subtype differentiation. Trends Endocrinol Metab 2005; 16: 114-119.

7- Kerstens M, Kobold M, Volmer M, Koerts J, Sluiter W, Dullaart R. Reference values for aldosterone-renin ratio in normotensive individuals and effects of changes in dietary sodium consumption. Clin Chem 2011; 57: 1607-1611.

8- Lackland DT, Weber MA. Global burden of cardiovascular disease and stroke: hypertension at the core. Can J Cardiol 2015; 31: 569-571.

9- Poulter NR, Prabhakaran D, Caulfield M. "Hypertension". Lancet 2015; 386: 801-812.

10- Chobanian AV, Bakris GL, Black HR, Cushman WC, Green LA, Izzo JL, Jones DW, Materson BJ, Oparil S, Wright JT, Roccella EJ. "Seventh report of the Joint National Committee on Prevention, Detection, Evaluation, and Treatment of High Blood Pressure". Hypertension 2003; 42: 1206-1252.

11- Delyani JA, Rocha R, Cook CS, Tobert DS, Levin S, Roniker B, et al. "Eplerenone: a selective aldosterone receptor antagonist (SARA)". Cardiovasc Drug Rev 2001; 19: 185-200.

12- Hill GS. Hypertensive nephroangiosclerosis. Curr Opin Nephrol Hypertens 2008; 17: 266-270. 